\title{
Effects of $n$-Octyl- $\beta$-D-Glucopyranoside on Human and Rat Erythrocyte Membrane Stability Against Hemolysis
}

\author{
Cesare Sblano, Silvia Micelli, Gabriella Notarachille and Daniela Meleleo* \\ Department Pharmaco-Biology, University of Bari “A. Moro”, via E. Orabona 4, 70126 Bari, Italy
}

\begin{abstract}
The practical importance for the pharmaceutical and cosmetics industries of the interactions between biological membranes and surfactant molecules has led to intensive research within this area. The interactions of non-ionic surfactant $n$-octyl- $\beta$-D-glucopyranoside (OG) with the human and rat erythrocyte membranes were studied. The in vitro hemolytic and antihemolytic activities were determined by employing a method in which both erythrocytes were added to the hypotonic medium containing OG at different concentrations, and the amount of haemoglobin released was determined. $n$ octyl- $\beta$-D-glucopyranoside was found to have a biphasic effect on both types of erythrocyte membrane. We also investigated the interactions of OG with the erythrocyte membrane in isotonic medium; the dose-dependent curves show similar behaviour in both human and rat erythrocytes. Our results showed that OG has greater antihemolytic potency on rat than on human erythrocytes; furthermore, rat erythrocytes were more sensitive than human erythrocytes to hypotonic shock. How the different lipoprotein structure of these erythrocytes determines a difference in antihemolytic activity is discussed.
\end{abstract}

Keywords: Antihemolytic potency, hypotonic hemolysis, $n$-octyl- $\beta$-D-glucopyranoside, non-ionic-surfactant.

\section{INTRODUCTION}

Surfactants are important ingredients in a number of chemical products that are widely used in modern daily life, such as cosmetics, medicines and household goods. As it is known that surface-active compounds can adversely affect the aquatic environment, the biodegradability and biocompatibility of surfactants have become almost as important for consumers as their functional performance. Surfactants are amphipathic molecules and contain a hydrophobic and a hydrophilic moiety, thus allowing them to interact with both polar and non-polar molecules, respectively. Surfactants are classified according to their chemical constitution and are usually divided into four classes: amphoteric, anionic, cationic and nonionic. Due to their amphipathic properties, surfactants can be used as cleaners, emulsifiers, foaming and wetting agents, etc.

Many authors have attempted to evaluate the potential risks of surfactants for human health by means of in vitro methods; a very common model for studying surfactant action was to measure the osmotic cell resistance of red blood cells (RBCs); it has been found that they present a biphasic effect: at low concentrations, they protect RBCs against hypotonic or mechanically induced lysis, whereas at higher concentrations they in fact induce RBC hemolysis [1]. The mechanism underlying the antihemolytic effect of surfactants is not fully understood. It is thought that, by intercalating into the lipid bilayer of the membrane, the surfactants expand the membrane, thereby allowing the cell to swell to a larger volume before it lyses [1]. This intercalation is apparently the primary step which triggers alteration in membranes. Some effects of surfactant molecules, such as

*Address correspondence to this author at the Department PharmacoBiology, University of Bari “A. Moro”, via E. Orabona 4, 70126 Bari, Italy; Tel/Fax:+390805442775; E-mail: dmeleleo@farmbiol.uniba.it protection against hypotonic hemolysis, seem to be the result of a nonspecific interaction between the bilayer and the detergent [2].

The hemolysis assay has became a classic tool for studying surfactants in drug-membrane interactions. To increase our knowledge regarding the possible action of surfactants on erythrocyte membranes, we investigated the action of the nonionic surfactant $n$-octyl- $\beta$-D-glucopyranoside (OG) on red blood cells under hypotonic conditions. OG is a nonionic and nontoxic surfactant which belongs to the alkylglucoside class $[3,4]$, its structure is similar to that of sugar monoester surfactants, which are used as nontoxic and easily biodegradable emulsifiers for human food [5]. OG is believed to be a "mild" surfactant in terms of its denaturing effects on protein and it also shows a relatively high critical micelle concentration $\left(\mathrm{CMC}=19-25 \mathrm{mM}\right.$ at $\left.25^{\circ} \mathrm{C}\right)[6]$.

In this work, we report on an experiment in which OG at low concentrations induces protection (membrane stabilization) against hypotonic hemolysis in rat and human erythrocytes.

\section{EXPERIMENTAL PROCEDURES}

\section{Surfactant}

The nonionic surfactant was $n$-octyl- $\beta$-D-glucopyranoside (OG) from Calbiochem USA 494459 (purity of 99\%), dissolved in PBS.

\section{Erythrocyte Preparation}

Human erythrocytes were obtained from the blood of healthy adult volunteers (Blood Bank at the Policlinico hospital, Bari, Italy), after informed consent had been obtained. Rat erythrocytes were obtained from the blood of male Wistar rats, weighing 250-300g. Rat were anesthetized 
with ethyl ether and blood collected from the abdominal aorta. All procedures were approved by our Animal Care Institute, and the animals were maintained in accordance with the Guide for the care and use of Laboratory Animals [7]. Erythrocytes were separated from blood plasma by centrifugation $\left(10 \mathrm{~min}\right.$ at $1500 \mathrm{~g}$ at $\left.4^{\circ} \mathrm{C}\right)$ and washed three times with PBS (137 mM NaCl, $2.7 \mathrm{mM} \mathrm{KCl}, 8 \mathrm{mM}$ $\mathrm{Na}_{2} \mathrm{HPO}_{4}, 1.15 \mathrm{mM} \mathrm{KH}_{2} \mathrm{PO}_{4}, \mathrm{pH} 7.4,300 \mathrm{mOsM}$ ) for $5 \mathrm{~min}$ at $1500 \mathrm{~g}$ at $4^{\circ} \mathrm{C}$. The supernatant and the buffy coat were carefully removed after each wash. The cells were then suspended at a cell density of $8 \times 10^{9}$ cell $/ \mathrm{ml}$. All experiments were carried out within $24 \mathrm{~h}$ of drawing the blood.

\section{Protection Against Hypotonic Hemolysis}

Our attempt was to compare the effects of $\mathrm{OG}$ in rat and human erythrocytes at the same OG concentration/RBC plasma membrane area. The surface area of rat/human erythrocytes has been estimated to be $121 / 140 \mu \mathrm{m}^{2}$, respectively [8]. Rat/human erythrocytes were therefore suspended in the buffer at a cell density of $2.0 \times 10^{8} / 1.74 \times 10^{8} \mathrm{cell} / \mathrm{ml}$, respectively; so that the total area of erythrocytes in the sample is almost the same (about $2.4 \times 10^{10} \mathrm{\mu m}^{2} / \mathrm{ml}$ ).

Surfactant antihemolysis was carried out in PBS to such an osmolarity that about $60-70 \%$ of untreated rat or human erythrocytes were hemolysed. A final cell density of $2.0 \mathrm{x}$ $10^{8}$ and $1.74 \times 10^{8}$ cells $/ \mathrm{ml}$ rat and human, respectively, was incubated with different concentrations of OG $(0.1 \mathrm{mM}$ $2 \mathrm{mM})$. Incubation was carried out in the vials, with constant shaking in a thermostat bath at $37^{\circ} \mathrm{C}$ for $60 \mathrm{~min}$. After incubation, erythrocytes were centrifuged for $10 \mathrm{~min}$ at $2000 \mathrm{~g}$ at $4^{\circ} \mathrm{C}$. Hemolysis was studied according to the method of Drabkin [9]. Cyanmethemoglobin was measured by spectrophotometry at a wavelength of $540 \mathrm{~nm}$ and absorbance values were converted to percentage hemolysis of the sample to that of the control totally hemolysed with distilled water. The antihemolytic potency of the surfactant was expressed as the percentage of hemolysis reduction compared with a surfactant-free specimen.

\section{Variations in Erythrocyte Volume}

The percentage expansion of red blood cell membranes induced by the surfactant was determined. The erythrocytes were incubated with $0.1,0.5,1.0$ and $2.0 \mathrm{mM}$ OG in PBS ranging between $105-300$ (mOsm/1) osmolarity. The percentage of hemolysis was determined as described above. The PBS concentration resulting in $50 \%$ hemolysis $\left(\mathrm{C}_{50 \%}\right)$ was determined by means of dose-response curves. During hypotonic hemolysis, the red cell volume increased from its initial value $\left(\mathrm{V}_{0}, \mathrm{MCV}=\right.$ mean corpuscular volume $)$ to the maximal volume, the so-called critical hemolytic volume $\left(\mathrm{V}_{\mathrm{h}}\right)$. According to Ponder [10], the relationship between $\mathrm{V}_{\mathrm{h}}$ and $\mathrm{C}_{50 \%}$ is described by the equation:

$$
\mathrm{V}_{\mathrm{h}}=\mathrm{V}_{\mathrm{na}}+\mathrm{V}_{\mathrm{a}}\left(\mathrm{C}_{\text {iso }} / \mathrm{C}_{50 \%}\right)
$$

which is applicable to mammalian red cell, where $V_{\text {na }}$ is the osmotically inactive volume representing $30 \%$ of the human and rat erythrocyte volume $\left(\mathrm{V}_{0}=87 / 56 \mathrm{fL}\right.$ for human/rat erythrocytes, respectively $[11,12]), \mathrm{V}_{\mathrm{a}}$ the osmotically active part of the erythrocyte volume representing $70 \%$ of $V_{0}$, and $\mathrm{C}_{\text {iso }}$ is the isosmotic concentration. The values taken for $\mathrm{V}_{\text {na }}$ $=26.1 / 16.8 \mathrm{fL}$ and $\mathrm{V}_{\mathrm{a}}=60.9 / 39.2 \mathrm{fL}$ for human $/ \mathrm{rat}$ erythrocytes respectively; $\mathrm{C}_{\text {iso }}=300 \mathrm{mOsm} / \mathrm{L} ; \mathrm{C}_{50 \%}=$ value in $\mathrm{mOsm} / \mathrm{L}$ determined for the control or for OG. The volume expansion can be calculated from the relationship between $V_{h}$ for the control and $V_{h}$ for the treated cells and expressed as a percentage [13-15].

\section{Statistical Analysis}

Significance differences were determined using analysis of variance and Student's t-test. (Graph Pad Prism ${ }^{\text {TM }}$ version 3.0; Graph Pad Software, Inc.). P-values $<0.05$ were considered significant.

\section{RESULTS}

In this paper, the effect of different concentrations of the non-ionic surfactant, $n$-octyl- $\beta$-D-glucopyranoside (OG), on human and rat erythrocytes in hypotonic shock is reported.

For the hemolysis test on rat and human erythrocytes, we used a medium diluted to a tonicity at which about $60-70 \%$ of untreated erythrocytes were hemolysed.

As a function of OG concentration, the curves of protection against hypotonic hemolysis were constructed, after which the concentration of $\mathrm{OG}$ producing the maximum

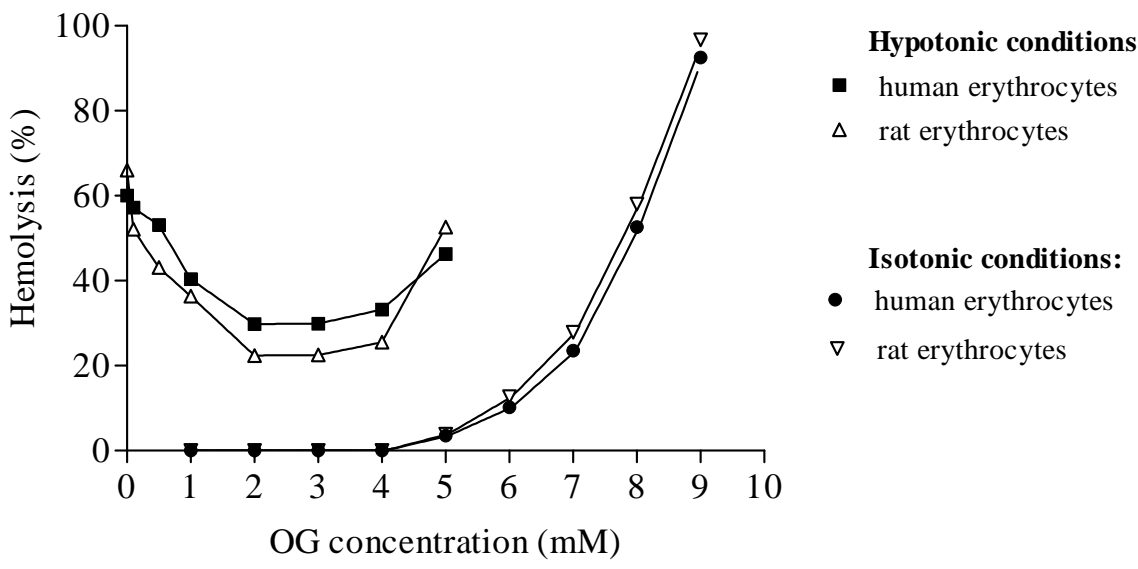

Fig. (1). The antihemolytic and hemolytic activity of OG on human and rat erythrocytes. The determination of OG antihemolytic potency was carried out in a medium of osmolarity causing $60-70 \%$ hemolysis of untreated erythrocytes or in isotonic conditions. Each point represents the mean of at least three separate experiments. 
protective effect was calculated; furthermore, isotonic medium was used to determine the OG concentration producing $50 \%$ hemolysis $\left(\mathrm{HC}_{50}\right)$.

The curve of protection against hypotonic hemolysis shows biphasic behaviour on the part of OG when it interacts with erythrocytes: i.e. low OG concentrations are antihemolytic and high OG concentrations are hemolytic. In fact, OG concentration in the range $0.1 / 0.2-3.0 \mathrm{mM}$ is protective for rat/human erythrocytes, respectively; by contrast, an OG concentration of over $5.0 \mathrm{mM}$ is lytic for both (Fig. 1).

If we compare the dose-response curves in hypotonic conditions of rat and human erythrocytes (Fig. 1), it can be seen that the antihemolytic activity of OG in rat erythrocytes is higher than in humans; in fact, at $0.1 \mathrm{mM} \mathrm{OG}$ the reduction in hemolysis is $2.8 \%$ in human erythrocytes compared to $26.9 \%$ in rat erythrocytes. The shape of the curves indicates that the antihemolysis is almost constant between 2-3 mM $\mathrm{OG}$, and then hemolysis increases linearly until at $5.0 \mathrm{mM}$ OG the cells are completely hemolysed. In the range 0.1-2.0 $\mathrm{mM}$ OG, human and rat erythrocytes are stabilized, hemolysis being reduced from $60 \%$ (without OG) to $29.8 \%$ (with OG) and from $66 \%$ (without OG) to $22.4 \%$ (with OG) in human and rat erythrocytes, respectively. The dosedependent curves in the isotonic medium (Fig. 1) show similar behaviour in both human and rat erythrocytes; in particular, it can be observed that hemolysis becomes manifest for $\mathrm{OG}$ concentrations higher than $4.0 \mathrm{mM}$ and increases on increasing the $\mathrm{OG}$ concentration up to $9.0 \mathrm{mM}$, at which point the cells are lysed. The $\mathrm{HC}_{50}$ is $8.35 / 8.21 \mathrm{mM}$ in human and rat erythrocytes, respectively.

Figs. (2 and 3) report the osmotic fragility curves. The shape of the curves is sigmoidal for both species and it can be seen that $\mathrm{OG}$ significantly protects erythrocytes from hypotonic lysis and reduces the concentration of the medium needed to cause $50 \%$ hemolysis. In fact, without OG, $50 \%$ hemolysis is achieved in human erythrocytes at $144 \mathrm{mOsM}$, whereas this value is reduced to $141.9 \mathrm{mOsM}, 139.0 \mathrm{mOsM}$ and $136.0 \mathrm{mOsM}$, at OG concentrations of $0.5 \mathrm{mM}, 1.0 \mathrm{mM}$ and $2.0 \mathrm{mM}$, respectively $(\mathrm{P}<0.05)$ (Fig. 2).

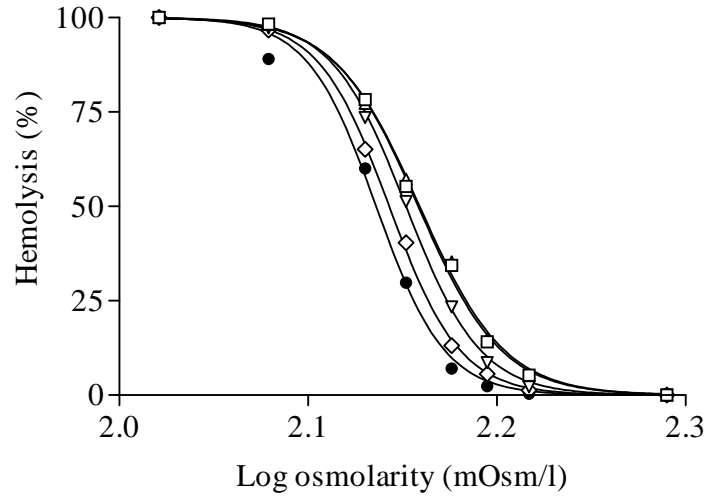

Fig. (2). Osmotic lysis of human erythrocytes in serial dilution of PBS. Solution in the absence and in the presence of OG. Symbol: $(\square)$ control; $(\Delta) 0.1 \mathrm{mM} \mathrm{OG} ;(\nabla) 0.5 \mathrm{mM} \mathrm{OG} ;(\diamond) 1.0 \mathrm{mM}$ $\mathrm{OG} ;(\bullet) 2 \mathrm{mM}$ OG. Each point represents the mean of at least three separate experiments.

Ponder's equation [10] allows to calculate the critical hemolytic volume. This value in human erythrocytes is 152.9 $\mathrm{fL}$ in hypotonic medium and $154.8 \mathrm{fL}, 157.5 \mathrm{fL}, 160.4 \mathrm{fL}$ at
OG concentrations of $0.5,1.0,2.0 \mathrm{mM}$, respectively, corresponding to a $\%$ increase of $1.2,3.0$ and 4.9 respectively.

In rat erythrocytes, $50 \%$ hemolysis is achieved at 151.7 mOsM in control conditions, and at $149.8 \mathrm{mOsM}, 145.5$ mOsM, $142.4 \mathrm{mOsM}, 139.7 \mathrm{mOsM}$, in the presence of 0.1 , $0.5,1.0$ and $2.0 \mathrm{mM}$ OG (Fig. 3). Furthermore, rat erythrocytes - but not human ones - are protected against osmotic shock at an OG concentration of $0.1 \mathrm{mM}(\mathrm{P}<0.05)$.

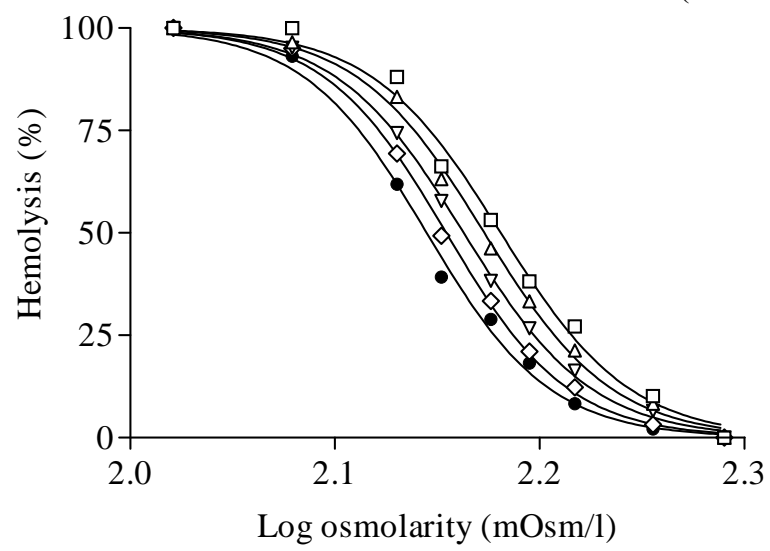

Fig. (3). Osmotic lysis of rat erythrocytes in serial diluition of PBS. Solution in the absence and in the presence of OG. Symbol: $(\square)$ control; $(\Delta) 0.1 \mathrm{mM} \mathrm{OG} ;(\nabla) 0.5 \mathrm{mM} \mathrm{OG} ;(\diamond) 1.0 \mathrm{mM} \mathrm{OG} ;(\bullet)$ $2 \mathrm{mM}$ OG. Each point represents the mean of at least three separate experiments.

Considering that the rat mean corpuscular volume (MCV) is about $56 \mathrm{fL}$ [12], the critical hemolytic volume is 94.3 fL in hypotonic control, and $95.7 \mathrm{fL}, 97.6 \mathrm{fL}, 99.3 \mathrm{fL}$, $100.8 \mathrm{fL}$ in the presence of $0.1,0.5,1.0,2.0 \mathrm{mM} \mathrm{OG}$, respectively, that corresponds to an increase in erythrocyte volume (\%) of 1.4, 3.4, 5.3 and 6.8 .

The lowest $\mathrm{OG}$ concentration required in rat/human erythrocytes to start the increase in critical hemolytic volume corresponds to $0.1 / 0.5 \mathrm{mM}$; while the maximum increase in the critical hemolytic volume is reached for both species at an $\mathrm{OG}$ concentration of $2.0 \mathrm{mM}$ (7.3fL and $6.0 \mathrm{fL}$ human and rat erythrocytes, with an increase in volume of $4.1 \%$ and $5.5 \%$, respectively).

Rat erythrocytes are more responsive to hypo-osmotic shock than human ones (Fig. 4), as found by other authors

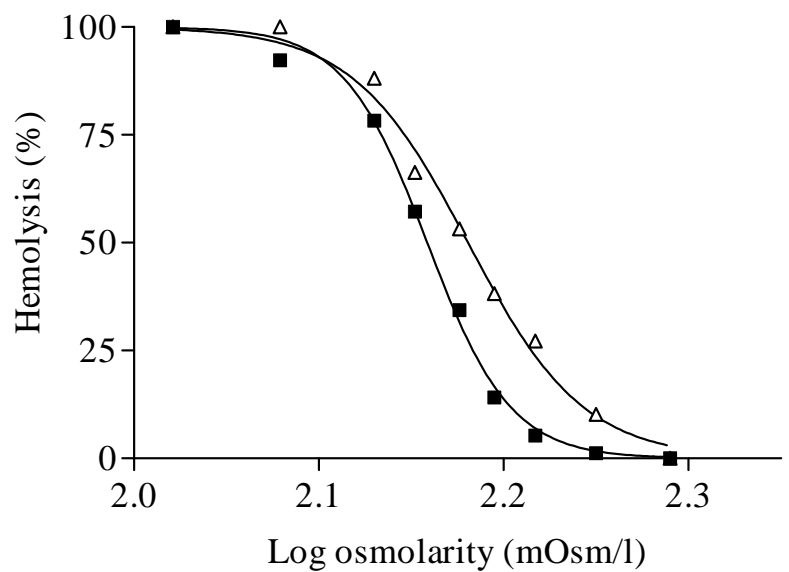

Fig. (4). Comparison of osmotic lysis of rat $(\Delta)$ and human ( $\mathbf{a})$ erythrocytes in serial dilution of PBS solution in OG absence. 
[16]; this could be correlated with: a-the different membrane protein pattern in rat and human erythrocytes, and b- to the different MCV: 87/56 fL human/rat.

Results from other experiments carried out by us (unpublished results) indicate that when the erythrocytes are subjected to lower osmotic stress (165-180 mOsM PBS), OG shows antihemolytic activity in rat erythrocytes at lower concentrations $(0.01 \mathrm{mM})$

\section{DISCUSSION}

Surfactants play an important role in the biochemical and biophysical characterization and purification of membrane proteins; furthermore, they are widely studied as enhancers of cell membrane permeability to drugs and as potential microbicides.

It has been proposed that the antihemolytic activity of lipid-soluble and amphipathic agents, such as surfactants, is due to their ability to expand the membrane, thereby increasing the critical hemolytic volume of the cells. In particular, surfactants interact with erythrocyte membranes in a biphasic manner: they are protective at low concentrations and cause lysis at higher concentrations [2]. However, the mechanism responsible for their antihemolytic effect is not yet understood.

Human erythrocytes do not behave as a perfect osmometer, i.e. their volume does not change as above with the increase or decrease in the tonicity of the medium, as if there was a fraction of cell water not participating in the osmotic exchange [10, 17-20].

The aim of this work was to study the effect of OG on human and rat erythrocytes in isotonic and hypotonic conditions

The results obtained show that like other surfactants, OG shows biphasic behaviour. It is worth noting that the difference in the responsiveness of the two erythrocyte membranes is evident, i.e., rat erythrocytes are more responsive than human erythrocytes; in fact, in hypotonic conditions, rat erythrocytes present an osmotic resistance at an OG concentration of $0.1 \mathrm{mM}$, while in the same conditions human erythrocytes require an $\mathrm{OG}$ concentration two to three times higher in order to manifest osmotic resistance, as would be expected from the different surface area/volume ratio $(\mathrm{S} / \mathrm{V})$.

The antihemolytic effect is a complex process in which the physical-chemical characteristics of surfactant and the membrane composition play a pivotal role. OG incorporating in the membrane expands erythrocyte volumes, as found for other surfactants. It has been demonstrated that surfactant molecules intercalated in the outer part of the bilayer change the shape of erythrocytes from discocytic to echinocytic with a corresponding increase in the difference between the surface area of the inner and outer leaflets of the bilayer [21, 22]. The red cells are stabilized by minimizing the elastic energy of the membrane, consisting of the bilayer bending energy, the bilayer relative stretching energy and the skeleton shear elastic energy [23]. In this context, the difference between the erythrocytes of the two species which present a different $\mathrm{S} / \mathrm{V}$ ratio of 1.61 and 2.01 for human and rat, respectively, must be considered.
The greater capacity of OG to stabilize rat erythrocytes is confirmed by the greater antihemolytic potency found experimentally in rat (66\%) compared to human erythrocytes $(50 \%)$ for the same hypotonic medium and OG concentration conditions. This different effect could be correlated to a different absorption of $\mathrm{OG}$ on the membrane bilayer and/or to the presence of different protein patterns in the two species studied.

It is worth noting that human and rat erythrocyte membranes differ in quality and quantity from membrane proteins as demonstrated by Seibert et al. [14]. In fact, the protein pattern found in human erythrocytes is spectrins, band 3 , protein $4.1,4.2,4.9,5$ and 6 ; whereas in rat it is spectrins, bands 3 and 3.1 , protein 4.1 and 4.2 together, protein 4.9 and 5. Furthermore, electrophoretic analysis showed that: a-the band 3 protein, the major component of membrane protein $(50 \%)$ responsible for $\mathrm{Cl}^{-} / \mathrm{HCO}_{3}^{-}$ exchange, is lower in rat; $b$ - the band 3.1 protein is absent in the human red blood cell membrane; and c- protein 6 is not expressed in rat. Sato et al., [24] studied the role played by band 3 protein in human erythrocytes during hypotonic or detergent-induced hemolysis. In hemolysis induced by detergent (SDS), the authors found a modification of membrane fluidity due to a rearrangement of lipids and other membrane components, while in hypotonic hemolysis a conformational and/or associative variation of membrane proteins was evident.

Furthermore, the same authors modified the band 3 protein by means of specific inhibitors, obtaining a dual effect: a- protection of cellular hemolysis through inhibition of water transport, b- variation in membrane proteins.

It could be supposed that the coexistence of the two experimental conditions (hypotonic medium plus detergent) inhibits band 3 protein activity.

The different protein pattern and the $\mathrm{S} / \mathrm{V}$ ratio would be responsible for a different absorption of surfactant on the membrane lipid bilayer.

OG is widely used as a detergent both because it is not protein denaturing, having a high CMC (19-25 mM) [25], and due to its very low toxicity in various biotechnological applications such as reducing hydrophobicity $[3,26]$. In fact, experiments carried out on the metabolism of orally administered alkyl $\beta$-glycosides in the mouse did not show toxic effects of the OG after administration of a dose of $2 \mathrm{~g} / \mathrm{Kg}$ body weight. OG is converted to common products of mammalian metabolism and seems not damage cells of stomach and intestine [5].

Seelig et al., [27] used H-NMR to demonstrate that OG perturbs the bilayer through fluctuations of acyl chains located at the hydrophobic core of the bilayer in a concentration-dependent manner. Studies of $\mathrm{OG}$ incorporation in planar lipid membranes (PLMs) of different composition have documented that $\mathrm{OG}$ at very low concentrations incurporates and forms ion channels through a toroidal mechanism in which membrane lipids and OG molecules cooperate to form transient shunts that that show selectivity characteristics depending on the membrane composition [28]. Consequently, a different use has been proposed, alongside the detergent effect, for example as a conditioning agent 
preventing the colonization and adhesion of Staphylococcus epidermidis and Pseudomonas aeruginosa to contact lenses, and as a promoter in transdermic formulations, specific carrier, physiological modulator, modulator of electroporation and/or as an agent in the noncovalent functionalization of carbon nanotubes.

The antihemolytic effect of OG may be due to its amphipathic properties, which favouring intercalation into the lipid bilayer, expand the membrane, so the swelling take place to a greater volume. However, if the number of surfactant molecules in the bilayer exceeds a certain level, the bilayer collapses and the cell will be lysed [2]. Such nonspecific interactions between OG and the erythrocyte membrane would give rise to membrane fluidity and permeability changes. It could be supposed that by forming channel-like pores in red blood cells just as it does in PLMs, OG forms transient shunts enabling fast ion efflux to balance the osmotic difference between the cytoplasm and the extracellular medium of the cell, thus allowing the cell to increase its swelling threshold.

The results of the present study could suggest a possible use of OG in all diseases in which erythrocyte fragility is manifest, such as in chronic renal failure (CRF) in which patients undergo hemodialysis. Studies to verify its helpfulness are in progress.

\section{CONFLICT OF INTEREST}

None declared.

\section{ACKNOWLEDGEMENTS}

The authors would like to thank Anthony Green for proofreading and providing linguistic advice.

\section{REFERENCES}

[1] Seeman P. The membrane action of anesthetics and tranquilizers. Pharmacol Rev 1972; 24: 583-655.

[2] Isomaa B, Hagerstrand H, Paatero G, Engblom AC. Permeability alterations and antihemolysis induced by amphiphiles in human erythrocytes. Biochim Biophiys Acta 1986; 860: 510-24.

[3] Holmberg K, Jonsson B, Kronberg B, Lindman B. Surfactants and polymers in acqueous solution. $2^{\text {nd }}$ ed. Hoboken, NJ: Wiley 2003.

[4] Elworthy PH, Treon JF. Physiological activity of non-ionic surfactants. In: Schick MJ, Ed. Nonionic surfactants. New York: Marcel Dekker 1967; vol. I: pp. 923-70.

[5] Weber N, Hildegard B. Metabolism of orally administered alkyl $\beta$ glycosides in the mouse. J Nutr 1984; 114: 247-54.

[6] Le Maire M, Champeil P, Møller JV. Interaction of membrane proteins and lipids with solubilizing detergents. Biochim Biophys Acta 2000; 1508: 86-111.

[7] NCR (National Research Council). Guide for the care and use of the Laboratory Animals. National Research Council. Washington USA: National Academy 1996.
[8] Gruber W, Deuticke B. Comparative aspects of phosphate transfer across mammalian erythrocyte membranes. J Membr Biol 1973; 13: 19-36.

[9] Drabkin DL, Aust HJ. Spectrophotometric studies. II. Preparations from washed blood cells; nitric oxide haemoglobin and sulphemoglobin. J Biol Chem 1935; 112: 51.

[10] Ponder E. Hemolysis and related phenomena. New York: Grune \& Stratton 1971.

[11] Richieri GV, Akeson SP, Mel HC. Measurement of biophysical properties of red blood cells by resistive pulse spectroscopy: volume, shape, surface area and deformability. J Biochem Biophys Methods 1985; 11: 117-31.

[12] Jain NC. Schalm's Veterinary Hematology. $4^{\text {th }}$ ed. Philadelphia: Lea \& Febiger 1986

[13] Jaruga E, Sokal A, Chrul S, Bartosz G. Apoptosis-independent alterations in membrane dynamics induced by curcumin. Exp Cell Res 1998; 245: 303-12.

[14] Seibert CS, Shinohara EMG, Sano-Martins IS. In vitro hemolytic activity of Lonomia oblique caterpillar bristle extract on human and Wistar rat erythrocytes. Toxicon 2003; 41: 831-9.

[15] Sánchez L, Martinez V, Infante MR, Mitjans M, Vinardell MP. Hemolysis and antihemolysis induced by amino acid-based surfactants. Toxicol Lett 2007; 169: 177-84.

[16] Udden MM. In vitro sub-hemolytic effects of butoxyacetic acid on human and rat erythrocytes. Toxicol Sci 2002; 69: 258-364.

[17] Dick DAT, Lowenstain LM. Osmotic equilibria inhuman erythrocytes studied by immersion refractometry. Proc R Soc Lond B Biol Sci 1959; 148: 214-56.

[18] Dalmark M. Chloride and water distribution in humanred cells. J Physiol 1975; 250: 65-84.

[19] Freedman JC, Hoffman JF. Ionic and osmotic equilibria of human red blood cells treated with nystatin. J Gen Physiol 1979; 74: 15785 .

[20] Solomon AK, Toon MR, Dix JA. Osmotic properties of human red cells. J Membr Biol 1986; 91: 259-73.

[21] Sheetz MP, Singer SJ. Biological membranes as bilayer couples. A mechanism of drug-erythrocyte interactions. Proc Natl Acad Sci USA 1974; 71: 4457-61.

[22] Isomaa B, Hagertrand H, Paatero G. Shape transformation induced by amphiphiles in erythrocytes. Biochim Biophys Acta 1987; 899: 93-103.

[23] Iglič A, Kralj-Iglic V, Hagerstrand H. Amphiphile induced echinocyte-spheroechinocyte transformation of red blood cell shape. Eur Biophys J 1998; 27: 335-9.

[24] Sato Y, Yamakose H, Suzuki Y. Participation of band 3 protein in hypotonic hemolysis of human erythrocytes. Biol Pharm Bull 1993; 16: 188-94.

[25] Stubbs GW, Gilbert Smith H, Litman BJ. Alkyl Glucosides as effective solubilizing agents for bovine rhodopsin. A comparison with several commonly used detergents. Biochim Biophiys Acta 1976; 425: 46-56.

[26] Santos L, Rodrigues D, Lira M, et al. The effect of octylglucoside and sodium cholate in Staphylococcus epidermidis and Pseudomonas aeruginose adhesion to soft contact lenses. Optom Vis Sci 2007; 84: 429-34.

[27] Seelig A, Seelig J, Alt T, Wenk MR. Octyl-beta-D-glucopyranoside partitioning into lipid bilayer:thermodinamics of binding and structural changes of the bilayer. Biophys J 1997; 72: 1719-31.

[28] Meleleo D, Micelli S, Stoico MG, Picciarelli V, Gallucci E. Can $n-$ octyl- $\beta$-D-glucopyranoside at fentomolar concentrations induce channel-like ionic pathways in planar lipid membranes?. In: Bernstein EM, Ed. Bioelectrochemistry research development. New York: Nova Science Publishers, Inc 2008; pp. 175-93. 